\title{
Formulation and Evaluation of Chitosan Based Transdermal Patches of Lornoxicam for Prolonged Drug Release and to Study the Effect of Permeation Enhancer
}

\author{
Adhikrao Vyankatrao Yadav 1 , Mukund Namdeo Urade 2 ,* \\ ${ }^{1}$ Gourishankar Institute of Pharmaceutical Education and Research, Limb, Satara- 415002, Maharashtra, INDIA. \\ ${ }^{2}$ Research Scholar, Government College of Pharmacy, Karad - 415110, Maharashtra, INDIA.
}

\begin{abstract}
Objective: The objectives of present investigation were to develop transdermal system for Lornoxicam using chitosan as rate controlling polymer and Tween 20 as permeation enhancer. Then evaluate the effect of Tween 20 on the physico-chemical properties of the patches and on drug permeation across the membrane. Methods: Transdermal patches of Lornoxicam were prepared by solvent casting method. The prepared patches were evaluated for physicochemical characteristics such as in vitro drug release, skin irritation studies. The interaction between drug and polymer were investigated by FTIR, DSC, XRPD methods. Results: The in vitro release studies revealed Formulation L4 containing higher concentration of Tween 20 showed $74.6 \%$ diffusion in $12 \mathrm{~h}$ and follows Korsmeyer-Peppas drug release kinetics. Respective formulation did not showed any sign of erythema or edema in skin irritation test. FTIR study reveals good compatibility between drug and polymer. Conclusion: The prepared transdermal drug delivery system of Lornoxicam using Chitosan had shown good promising results for sustained release matrix transdermal patch formulation.
\end{abstract}

Key words: Transdermal patches, Chitosan, Lornoxicam, Tween 20, in-vitro release studies.

\section{INTRODUCTION}

Transdermal drug delivery system provides controlled drug release through skin to reach systemic circulation. Transdermal delivery also has leading edge over oral route by avoiding first pass metabolism of drugs. Transdermal delivery serves variety of advantages compared with the traditional oral route of drug administration. Transdermal drug delivery systems are noninvasive and inexpensive, self-administered, improve patient compliance and can provide release of drugs for long periods of time. The challenge remains for transdermal delivery is that only limited number of drugs is amenable to administration by this route. ${ }^{1}$ Treatment of chronic diseases/disorders such as asthma, rheumatoid arthritis by transdermal route of drug administration might prove to have several advantages over other routes of drug administration. ${ }^{2}$

Chitosan is $N$-deacetylated derivative of chitin, semi-rigid polysaccharide, which is composed of $N$-acetyl D-glucosamine and D-glucosamine. Chitosan is a promising biomaterial in view of its biodegradability; biocompatibility and nonantigenecity. ${ }^{3} \mathrm{Chi}$ tosan has bio-adhesive or mucoadhesive property that readily binds to negatively charged surfaces such as mucosal membranes. Chitosan greatly enhances the transport of polar drugs across epithelial surfaces. Chitosan is insoluble in neutral and basic environments due to lack of positive charge. Chitosan has a positive charge under acidic conditions due to protonation of free amino groups which enhances the solubility. ${ }^{4}$
Submission Date: 31-03-2018; Revision Date: 14-08-2018; Accepted Date: 23-10-2018

DOI: 10.5530/ijper.53.1.12 Correspondence: Mr. Mukund N. Urade, Government College of Pharmacy, Vidyanagar, Taluka Karad- 41511, District Satara, Maharashtra, INDIA. Phone: +919890111816 E-mail: mukundurade@ gmail.com

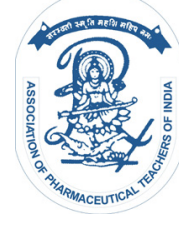

www.ijper.org 
It was observed that chitosan is used as a biopolymer in controlling the release rate of the drug in transdermal drug delivery systems. Stratum corneum region comprises tight junctions between the cells which bear negative charges similar to epithelial cells. Chitosan due to its bio-adhesive property as well as the percutaneous penetration enhancement activity, it plays an important role in the interaction between its positive charges and negative charges of skin. ${ }^{5}$ Due to unique polymeric cationic character, Chitosan has gel and film forming properties. Therefore chitosan has been extensively examined in the pharmaceutical industry for its potential use in the development of transdermal drug delivery systems. $^{6}$

Lornoxicam is the newer and potent NSAIDs that inhibit cyclo-oxygenase enzyme of arachidonic acid pathway that results into inhibition of prostaglandin synthesis. Lornoxicam acts as a useful anti-inflammatory agent to control rheumatoid arthritis and postoperative pains. Lornoxicam suffers from serious drawbacks like non-compliance due to frequent dosing and various side effects like gastro-intestinal irritation and ulcerogenicity. Rapid and complete absorption of Lornoxicam takes place through the gastrointestinal tract. Lornoxicam has shorter plasma half-life ( 3 to $5 \mathrm{~h}$ ) and maximum plasma concentration is attained within $2.5 \mathrm{~h} .{ }^{8}$ Thus, Lornoxicam is a suitable candidate for transdermal drug delivery system. Literature reveals that attempts have been made to formulate transdermal patches of Lornoxicam by using different polymers such as Poly vinyl alcohol, Ethyl cellulose, ${ }^{7}$ Hydroxypropyl methylcellulose and Eudragit RS- $100^{9}$ to improve drug diffusion for prolonged duration of time. Eugenol and cineole also used as permeation enhancer to improve drug diffusion. ${ }^{8}$ Honglei et al. 2013 have also systemically investigated intra-articular delivery of teriflunomide and Lornoxicam for enhance a local treatment for rheumatoid arthritis. ${ }^{10}$ Yene et al. 2010 have earlier reported the transdermal patch using Hydroxypropyl methylcellulose for meloxicam and lornoxicam drugs. ${ }^{11}$ Also, Lornoxicam Patch was prepared by patel et al. 2016 using the solvent casting method containing HPMC various grade and Eudragit RS 100 as a polymer, PEG-400 and Tween 80 uses as plasticizer, Methanol and Dichloromethane used as solvent. ${ }^{12}$ To date, there are no research papers available on the transdermal patches of Lornoxicam prepared by using chitosan as release controlling polymer and Tween 20 as permeation enhancer. Therefore the objective of our research paper was to develop chitosan containing transdermal patches of Lornoxicam which could produce a constant and prolonged release of the drug, also to evaluate the effect of Tween 20 on the physico-chemical properties of the patches and on drug permeation across the membrane.

\section{MATERIALS AND METHODS}

Lornoxicam was a gift sample obtained from Abbott Pharmaceuticals Ltd. Mumbai. The polymers such as Chitosan obtained from Mahtani Chitosan, Veraval. All other chemicals and reagents were of analytical grade and obtained from Loba Chemie Pvt. Ltd. Mumbai.

\section{Preparation of patches by solvent casting method}

Matrix type transdermal patches containing Lornoxicam were prepared by solvent casting technique employing a mercury substrate. The patches were casted into glass rings having $4 \mathrm{~cm}$ diameter placed on a mercury surface contained in a Petri plate. $1.5 \%$ Chitosan having deacetylation degree $80 \%$ was dissolved in $1 \%$ glacial acetic acid solution. $2 \%$ Propylene glycol was used as plasticizer and different concentrations of Tween 20 were used as permeation enhancer. Sufficient quantity of drug was added in solution so that each patch should have $8 \mathrm{mg}$ of Lornoxicam. The drug solution was poured over the surface of mercury which contains glass ring having $4 \mathrm{~cm}$ diameter. These patches were covered with a funnel in an inverted position. The solvent was allowed to evaporate at ambient conditions for $24 \mathrm{~h}$. After drying, the patches were packed in aluminum foil and stored in desiccators. ${ }^{13}$ Compositions of different formulations were listed in Table 1.

\section{Characterization of Transdermal Patches}

Morphological properties: Patches were evaluated by visual observation such as color, flexibility and smoothness. ${ }^{14}$

\section{Weight variation and thickness}

Weight variation was determined by weighing three patches individually from each batch on an electronic balance (Schimadzu) and calculating the mean and standard deviation. The thicknesses of the transdermal patches were measured at three different points using a digital vernier caliper and the average thickness was recorded.

\section{Drug content}

Drug content uniformity of Lornoxicam patches were determined by dissolving the patches by homogenization in $100 \mathrm{~mL}$ of phosphate buffer $(\mathrm{pH}$ 7.4). The contents were stirred using a magnetic bead to dissolve the patches. After suitable dilution, the resultant solution was filtered through $0.45 \mu \mathrm{m}$ whatman filter paper. The drug content was determined at $376 \mathrm{~nm}$ against the 


\begin{tabular}{|c|c|c|c|c|}
\hline Formulation & L1 & L2 & L3 & L4 \\
\hline Chitosan (\%) & 1.5 & 1.5 & 1.5 & 1.5 \\
\hline Glacial Acetic acid (\%) & 1 & 1 & 1 & 1 \\
\hline Propylene Glycol (\%) & 2 & 2 & 2 & 2 \\
\hline Tween 20 (\%) & - & 1 & 1.5 & 2 \\
\hline Lornoxicam mg & $\begin{array}{l}\text { Drug incorporated in } \\
\text { each patch }-8 \mathrm{mg}\end{array}$ & & & \\
\hline
\end{tabular}

reference solution containing placebo patches of chitosan using a UV-spectrophotometer (Jasco, V-530 and Japan). The experiments were carried out in triplicate and average values were reported. ${ }^{15}$

\section{Folding endurance test}

Folding endurance test was measured manually for the prepared patches. The test was performed by folding the patch at the same place till it broke. The number of times the Lornoxicam patches could be folded without breaking gave the folding endurance value. ${ }^{14}$ This test reveals the efficiency of plasticizer and the strength of the prepared patches. This test is repeated three times for reproducibility. ${ }^{8}$

\section{Moisture Uptake}

The films were weighed accurately and kept in desiccator at a relative humidity of $75 \%$ (a saturated solution of sodium chloride). After $24 \mathrm{~h}$, the patches were reweighed and the percentage moisture uptake was calculated using the following formula. ${ }^{8}$

$\%$ Moisture Uptake $=($ Final Weight - Initial Weight $)$ /Initial Weight $\times 100$

\section{Percentage moisture loss}

Three patches from each formulation were weighed accurately and kept in a desiccator containing fused anhydrous calcium chloride. After $72 \mathrm{~h}$, the patches were removed and weighed accurately. Average percentage moisture losses of three patches were found out. ${ }^{16}$

Percentage of moisture loss was calculated by using the following formula

$\%$ Moisture Loss $=($ Initial Weight - Final Weight $) /$

\section{Water Vapor Transmission Rate (WVTR)}

Vials of equal diameter were used as transmission cells for this study. The vials were washed properly and dried in an oven. In these vials, about $1 \mathrm{~g}$ of fused calcium chloride was taken and the patches were fixed over the brim of vials with the help of an adhesive tape. After this, vials were weighed accurately and initial weight of the vials was recorded. These vials kept in a desiccator containing saturated solution of potassium chloride which can maintain relative humidity about $80-90 \%$. The vials were taken out and weighed after $72 \mathrm{~h}$. Water vapour transmission rate is usually expressed as the number of grams of moisture gained $72 \mathrm{~h} / \mathrm{cm}^{2}$. Water vapor transmission rate was calculated by using following formula. ${ }^{15}$

$$
\mathbf{W V T}=\mathrm{WL} \div \mathrm{S}
$$

Where, $\mathrm{W}$ is expressed as transmitted water vapour in $\mathrm{mg}, \mathrm{L}$ is patch thickness in $\mathrm{mm}, \mathrm{S}$ is exposed surface area in $\mathrm{cm}^{2}$.

\section{In vitro Drug Release Studies}

In vitro drug release studies were performed by using a Franz diffusion cell with a receptor compartment capacity of $17 \mathrm{~mL}$. The cellulose acetate membrane was used for the determination of drug from the transdermal patches. The cellulose acetate membrane having a pore size $0.45 \mu$ was used for diffusion study and this cellulose acetate membrane was mounted between the donor and receptor compartment of the Franz diffusion cell. Transdermal patch of Lornoxicam was placed on the cellulose acetate membrane and covered with aluminum foil. The phosphate buffer $\mathrm{pH} 7.4$ was filled in the receptor compartment of the Franz diffusion cell. Assembly was fixed on a hot plate magnetic stirrer; and constant stirring in the receptor compartment was maintained by using magnetic beads.

The temperature of healthy human skin normally remains at $32^{\circ} \mathrm{C}$, so the temperature of the diffusion system was maintained at range of $32 \pm 0.5^{\circ} \mathrm{C}$. The samples from diffusion cell were withdrawn at different time intervals and analyzed for drug content spectrophotometrically at $376 \mathrm{~nm}$. The receptor compartment was replenished with an equal volume of phosphate buffer after each sample withdrawal. ${ }^{17}$

\section{Skin irritation test}

All animal experiments were carried out in accordance with the guidelines of CPCSEA and the protocol was 
approved by the Institutional Animal Ethical Committee, Appasaheb Birnale College of Pharmacy, Sangli (IAEC/ABCP/14/2015-16). An optimized patch was evaluated for skin irritation test on female albino rats having weight about 180- $220 \mathrm{gm}$. The irritancy of the selected patches was evaluated by the method described by Draize et al. Thiopental sodium $60 \mathrm{mg} \mathrm{kg}^{-1}$ was given by i.p. route to induce anesthesia in rats. The dorsal side of the female rat was shaved with clippers $24 \mathrm{~h}$ before the beginning of the skin irritation test. Animals were divided into three groups consisting of 6 rats each: Group A served as control, Group B received $0.5 \mathrm{~mL}$ of a $0.8 \% \mathrm{~V} / \mathrm{V}$ aqueous formalin solutions a standard irritant. Group $C$ received medicated patches for 3 day (A new patch was applied daily). The application sites were examined for edema and erythema after 24 and 72 $\mathrm{h}$, then graded (0-4) according to a visual scoring scale always by the same investigator; the final score represents the average of the 24 and $72 \mathrm{~h}$ readings. The erythema scale was as: 0 - None; 1 - Slight; 2 - Well defined; 3 - Moderate; and 4 -Scare formation. The edema scale was: 0 - None; 1 - Slight; 2 - Well defined; 3 - Moderate; and 4 -Severe. The primary irritancy index (PII) was determined for each preparation by adding the edema and erythema scores, the formulations were accordingly classified as non-irritant if $\mathrm{PII}<2$, irritant if $(\mathrm{PII}=2-5)$ and highly irritant if PII $=5-8 .{ }^{18}$

\section{Fourier transformation-infrared spectroscopy (FT-IR)}

FT-IR technique was used to study the physical and chemical interaction between drug and other excipients ${ }^{19}$ Infrared spectroscopy in conjunction with Attenuated Total Reflectance is a sampling technique used for sample examination. Infrared spectra of Lornoxicam patches were obtained by using ATR (BRUKER - ECO - ATR - ALPHA, GERMANY). The samples were directly placed on sample pan and analyzed from 600 to $4000 \mathrm{~cm}^{-1}$ spectral range with 24 scans.

\section{Differential scanning colorimetry (DSC)}

Thermograms of drug and patches were obtained using DSC analyzer (Pyris Diamond TG/DTA, Make-Perkin Elmer) equipped with an intra-cooler. Platinum crucible used with alpha alumina powder as a reference to calibrate the DSC temperature and enthalpy scale. The samples were heated at a constant rate $10^{\circ} \mathrm{C}$ per min, over a temperature range of $35-250^{\circ} \mathrm{C} .{ }^{20}$

\section{X-ray powder diffractometry (XRPD)}

$\mathrm{X}$-ray diffraction analysis was employed to detect the crystallinity of the pure drug and the formulation. Transdermal patchesand pure drug was subjected to
p-XRD study using X-ray diffractometer (Philips X-ray diffractometer, PW-3710). Samples were irradiated with monochromatized $\mathrm{Cu} \mathrm{K} \alpha$ radiation and analyzed between $10^{\circ}$ to $70^{\circ} . .^{20}$

\section{RESULTS AND DISCUSSION}

\section{Morphological properties}

Prepared patches were found to be smooth, flexible and homogeneous. The prepared formulation was evaluated for different physico-chemical properties shown in Table 2.

\section{Weight variation and thickness}

The weight of patches varied from $132.27 \pm 2.61$ to $137.5 \pm 4.76 \mathrm{mg}$. The thickness of the patches varied from $0.18 \pm 0.003$ to $0.21 \pm 0.007 \mathrm{~mm}$.

\section{Drug content}

Drug content was found to be in the range of 96.77 to $98.41 \%$. Drug content of formulation L4 was found to be higher than other formulations.

\section{Folding endurance test}

The folding endurance test was performed manually; the patches were folded 67 times maximum in the formulation L1. If the patches show any cracks on their surface, it was considered as end point (Table 2).

\section{Percentage moisture loss}

The percentage of Moisture loss of the prepared transdermal patches was found to be in between 7.92 to 9.55 (Table 2).

\section{Moisture uptake}

The percentage of Moisture uptake of the prepared transdermal patches was found to be in between 5.43 to 7.07 (Table 2).

\section{Water vapor transmission rate (WVTR)}

Water vapor transmission rate reveals the permeability characteristics of patches. Water vapor transmission rate of prepared transdermal patches of Lornoxicam was found to be between 0.00029 to 0.00041 (Table 2).

Table 2 shows data of moisture loss, moisture uptake and water vapor transmission rate. It was evident that all these physicochemical parameters increased gradually in the formulations from L1 to L4 with increase in the concentration of tween 20 . This factor has affected the folding endurance (Table 2) of the films notably. The folding endurance property was observed to be gradually decreased in the formulations from L1 to L4 with increase in the brittleness resulting in the less stability. 


\begin{tabular}{|c|c|c|c|c|c|c|c|}
\hline \multicolumn{7}{|c|}{ Table 2: Physicochemical Evaluation data of Lornoxicam Transdermal Patches. } \\
\hline $\begin{array}{c}\text { Formulation } \\
\text { Code }\end{array}$ & $\begin{array}{c}\text { Weight } \\
\text { Uniformity } \\
(\mathbf{m g}) \pm \text { SD }\end{array}$ & $\begin{array}{c}\text { Thickness } \\
(\mathbf{m m}) \pm \text { SD }\end{array}$ & $\begin{array}{c}\text { Drug Content } \\
\mathbf{( \% )}\end{array}$ & $\begin{array}{c}\text { Folding } \\
\text { Endurance } \\
\pm \text { SD }\end{array}$ & $\begin{array}{c}\text { \% w/w } \\
\text { Moisture } \\
\text { Loss } \pm \text { SD }\end{array}$ & $\begin{array}{c}\text { \%oisture } \mathbf{w} / \mathbf{m} \\
\text { Uptake } \pm \text { SD }\end{array}$ & $\begin{array}{c}\text { Water Vapor } \\
\text { Transmission } \\
\text { rate } \\
(\mathbf{g m} / \mathbf{c m} / \mathbf{h r})\end{array}$ \\
\hline L1 & $135.03+3.76$ & $0.18+0.003$ & $96.77+1.04$ & $67.00+4.58$ & $7.92+0.39$ & $5.43 \pm 1.16$ & 0.00029 \\
\hline L2 & $132.27+2.61$ & $0.20+0.020$ & $97.18+1.68$ & $64.67+4.51$ & $8.7+2.63$ & $6.36 \pm 0.25$ & 0.00037 \\
\hline L3 & $136.90+1.25$ & $0.21+0.005$ & $97.76+1.42$ & $62.33+4.51$ & $9.26+0.95$ & $6.96 \pm 0.52$ & 0.00040 \\
\hline L4 & $137.50+4.76$ & $0.21+0.007$ & $98.41+0.91$ & $59.00+3.61$ & $9.55+0.71$ & $7.07 \pm 1.53$ & 0.00041 \\
\hline
\end{tabular}

It has been reported that the patches incorporated with hydrophilic polymers experience less water loss having lower brittleness with good stability. ${ }^{21}$ Thus, the formulation L4 had higher brittleness compared to the others due to greater amount of tween 20 having limited solubility. Further the chitosan having variable solubility in aqueous acidic solvents depending on the degree of acetylation might have contributed for the results. Indeed, it would be expected that the higher water loss would protect the formulation from microbial contamination and reduce the bulkiness over the period of time.

\section{In vitro Drug Release Studies}

In-vitro drug release studies were carried out using Franz diffusion cell. The result of diffusion studies indicates that Formulation L4 containing higher concentration of Tween $20(2 \%)$ increases drug diffusion $74.6 \%$ in 12 h. Formulation L1 without having Tween 20 concentration shows minimum drug release $36.46 \%$ in $12 \mathrm{~h}$.

From the above result, it is concluded that Tween 20 increases permeation of lornoxicam in concentration dependent manner. Tween 20 may decrease the resistance for the diffusion of drug. Tween 20 promotes adsorption and fusion of drug molecules across the barrier membrane, resulting into enhanced thermodynamic activity. The enhanced activity of tween 20 due to saturated hydrophobic group at $\mathrm{C}_{12}$ position responsible for micellar complexation. ${ }^{22}$

The percentage of cumulative drug release was plotted against Time (hr) to obtain release profile shown in Figure 1.

\section{Kinetic modelling of drug release}

The drug release kinetics (correlation coefficient $r^{2}$ ) obtained from zero order, first order; Korsmeyer- Peppas, Higuchi and Hixon-Crowell models fitted for transdermal patches have been shown in Table 3.

The release profile of Lornoxicam patches followed Korsmeyer-Peppas kinetics in different formulation. The ' $n$ ' value range was found to be $0.925-1.080$. The ' $n$ '

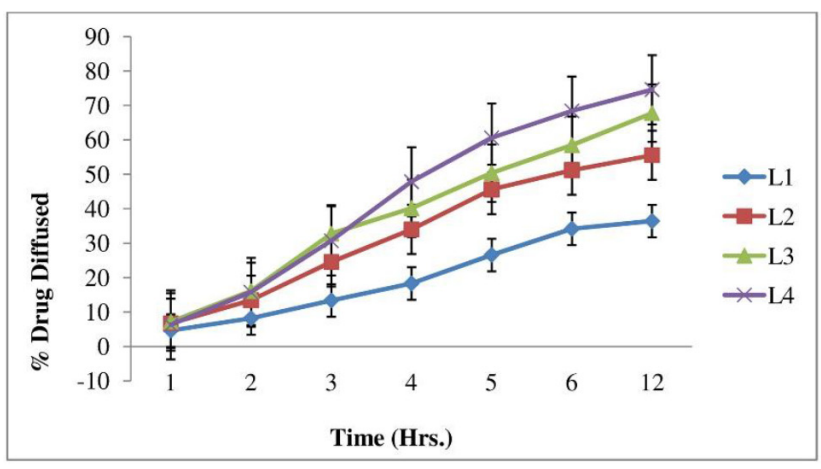

Percentage cumulative drug diffused vs. Time (hr.)

Figure 1: Percentage cumulative drug diffused vs. Time (hr.)

\begin{tabular}{|c|c|c|c|c|c|c|}
\multicolumn{7}{|c|}{ Table 3: Drug release kinetics (Coefficient of } \\
correlation $\left.\mathbf{r}^{2}\right)$. \\
\hline $\begin{array}{c}\text { Batch } \\
\text { Code }\end{array}$ & $\begin{array}{c}\text { Zero } \\
\text { order }\end{array}$ & $\begin{array}{c}\text { First } \\
\text { Order }\end{array}$ & Higuchi & $\begin{array}{c}\text { Hixson- } \\
\text { Crowell }\end{array}$ & $\begin{array}{c}\text { Korsmeyer- } \\
\text { Peppas }\end{array}$ \\
\hline L1 & 0.784 & 0.674 & 0.880 & 0.797 & 0.936 & 0.925 \\
\hline L2 & 0.743 & 0.605 & 0.869 & 0.777 & 0.915 & 0.933 \\
\hline L3 & 0.792 & 0.599 & 0.911 & 0.856 & 0.915 & 0.962 \\
\hline L4 & 0.734 & 0.570 & 0.863 & 0.798 & 0.901 & 1.080 \\
\hline
\end{tabular}

values obtained from Korsmeyer-Peppas model show combination of Non-fickian release mechanism and Super case II transport.

\section{Skin irritation test}

Based on higher drug permeation, formulation L4 was selected for the skin irritation test. When the animals are examined at 24 and $72 \mathrm{~h}$ after the application of transdermal patch, it was found that formulation did not show any sign of either edema or erythema. The primary irritancy index (PII) of control and medicated patches was found to be $<2$ and that of formalin treated group, PII was found to be $5.67 \pm 0.52$ which is considered as highly irritant. According to Draize et al. formulations showing PII $<2$ considered as non-irritant. Thus, Lornoxicam patches found to be non-irritant, safe to 


\begin{tabular}{|c|c|c|c|c|c|c|}
\hline Functional Group & L1 & L2 & L3 & L4 & Lornoxicam & Chitosan \\
\hline O-H Stretching & 3546 & 3376 & 3378 & 3401 & -- & 3282 Overlapping \\
\hline C-S Stretching & 1235 & 1237 & 1236 & 1262 & 1237 & -- \\
\hline $\mathrm{C}=\mathrm{C}$ aromatic Stretching & 1578 & 1582 & 1583 & 1580 & 1592 & \\
\hline C-Cl Stretching & 922 & 923 & 922 & 942 & 984 & -- \\
\hline $\mathrm{S}=\mathrm{O}$ asymmetric stretching & 1332 & 1331 & 1330 & 1331 & 1323 & -- \\
\hline C-N stretching & 1425 & 1427 & 1426 & 1427 & -- & 1418 \\
\hline $\mathrm{N}-\mathrm{H}$ Stretching $\left(\mathrm{NH}_{2}\right)$ & 3263 & Overlapping & Overlapping & Overlapping & -- & 3282 Overlapping \\
\hline C-H stretching Aliphatic & 2923 & 2924,2878 & 2924,2878 & 2920,2874 & 2771 & 2867 \\
\hline $\mathrm{N}-\mathrm{H}$ bending & 1530 & 1530 & 1529 & 1530 & 1536 & -- \\
\hline $\mathrm{O}-\mathrm{H}$ bending & 1400 & 1399 & 1398 & 1398 & 1380 & \\
\hline $\mathrm{C}-\mathrm{O}-\mathrm{C}$ bending & 1039 & 1041 & 1041 & 1086 & -- & 1064 \\
\hline $\mathrm{C}=\mathrm{O}$ Amide & 1742 & 1637 & 1638 & 1731 & 1641 & 1585 \\
\hline C-H Aromatic & 3097 & -- & 3097 & -- & 3062,3097 & -- \\
\hline $\mathrm{C}=\mathrm{N}$ stretching & -- & -- & -- & -- & 1423 & -- \\
\hline
\end{tabular}

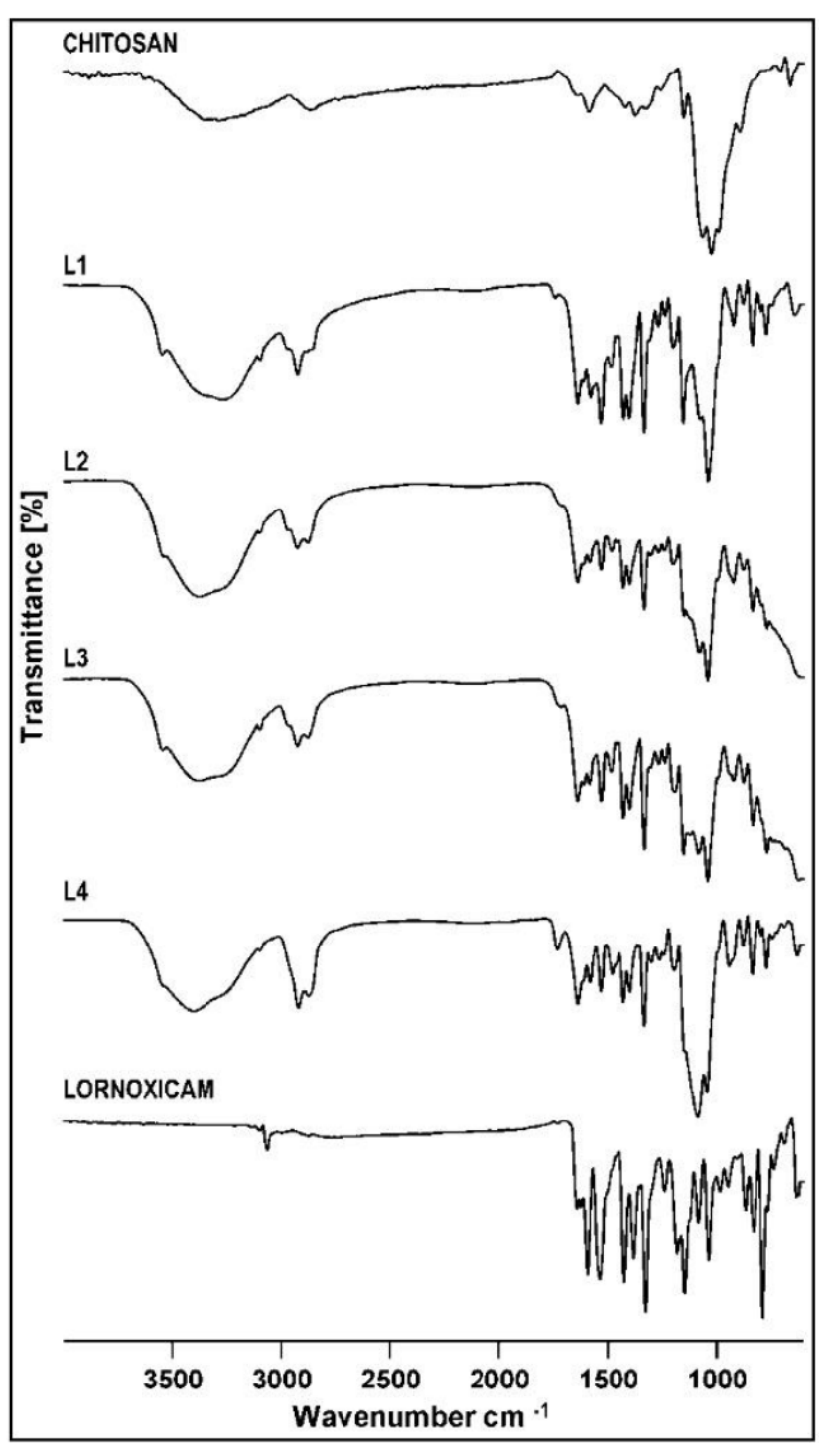

Figure 2: Fourier transforms infrared spectroscopy (FT-IR). be applied on the skin for the intended period of time (Figure 5).

\section{Fourier transforms infrared (FT-IR) spectroscopy}

The pure drug, prepared formulations of lornoxicam and polymers were subjected to FT-IR studies alone and in combinations to study there is no interference of polymer and drug. Pure Lornoxicam was characterized by intense stretching and weak bending bands as shown in the table. The peak of hydroxyl group in pure Lornoxicam appeared broad which might be attributed to strong hydrogen bonding with adjacent carbonyl group. The IR spectrum of chitosan was characterized by broad band at $3282 \mathrm{~cm}^{-1}\left(\mathrm{OH}\right.$ and $\left.\mathrm{NH}_{2}\right)$. A small peak at $2867 \mathrm{~cm}^{-1}$ appeared due to aliphatic stretching of (C-H). A glycosidic linkage (C-O-C) in chitosan could be assignable at $1064 \mathrm{~cm}^{-1}$. All formulations exhibited shifting, attenuation and /or disappearance of bands of pure Lornoxicam indicating strong physical interaction between the drug and polymer suggesting good compatibility between them. No new bands appeared in any formulation indicating an absence of any chemical interaction between the drug and polymer. Results are shown in Table 4 and Figure 2.

\section{Differential scanning calorimetry (DSC)}

The DSC thermograms of the pure Lornoxicam and formulations are shown in Figure 3. Pure Lornoxicam melt in the range of $225-230^{\circ} \mathrm{C} .^{23}$ All formulations have shown water loss in the temperature range of 78.51 to 84.96 with the appearance of broad thermograms. When the drug is incorporated in the polymer matrix, its peaks usually shift, attenuate, disappear or sometimes 


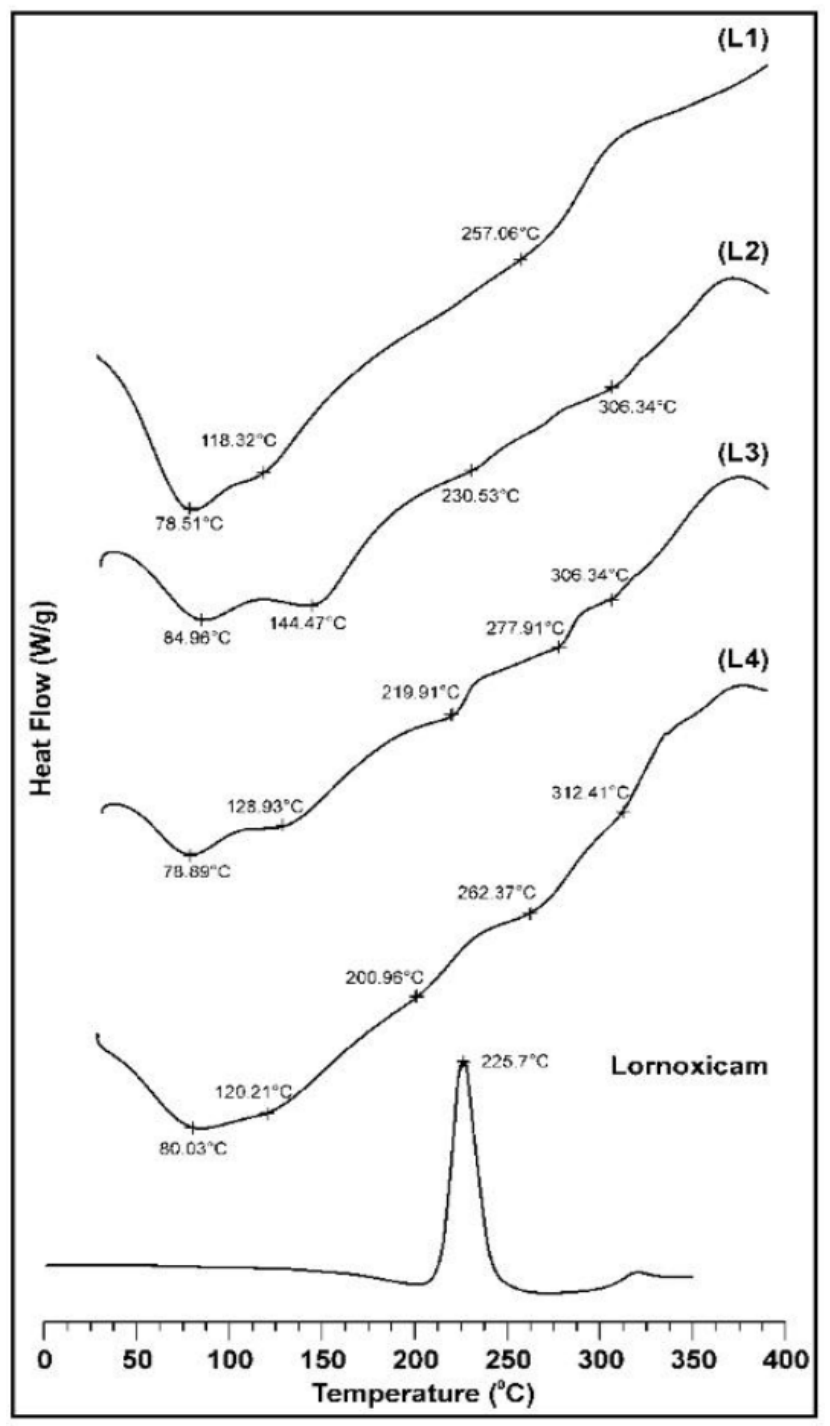

Figure 3: DSC Spectra.

may not be detectable. However, weak and broad peaks of Lornoxicam are visible in the formulations, ranging from 200 to $230^{\circ} \mathrm{C}$. A complete disappearance of Lornoxicam peak was seen in L1. Thus, Lornoxicam has experienced strong physical interactions with polymers with uniform dispersion in the formulations.

\section{X-ray powder diffractometry (XRPD)}

The XRPD patterns of pure Lornoxicam and formulations are displayed in Figure 4. As expected and shown in DSC, Lornoxicam exhibited sharp characteristic intensities at $2 \theta$ of $8.86,12.72,13.68,14.65,18.51$, $21.41,22.37,24.30,25.27,28.17$ and 30.10 indicating its crystalline nature. However, from the XRPD patterns of formulations L1 to L4, it was noticeable that the crystalline peaks of Lornoxicam were diffused in the formulations. Interestingly, some crystalline peaks were still detectable. Certain peaks might have appeared due

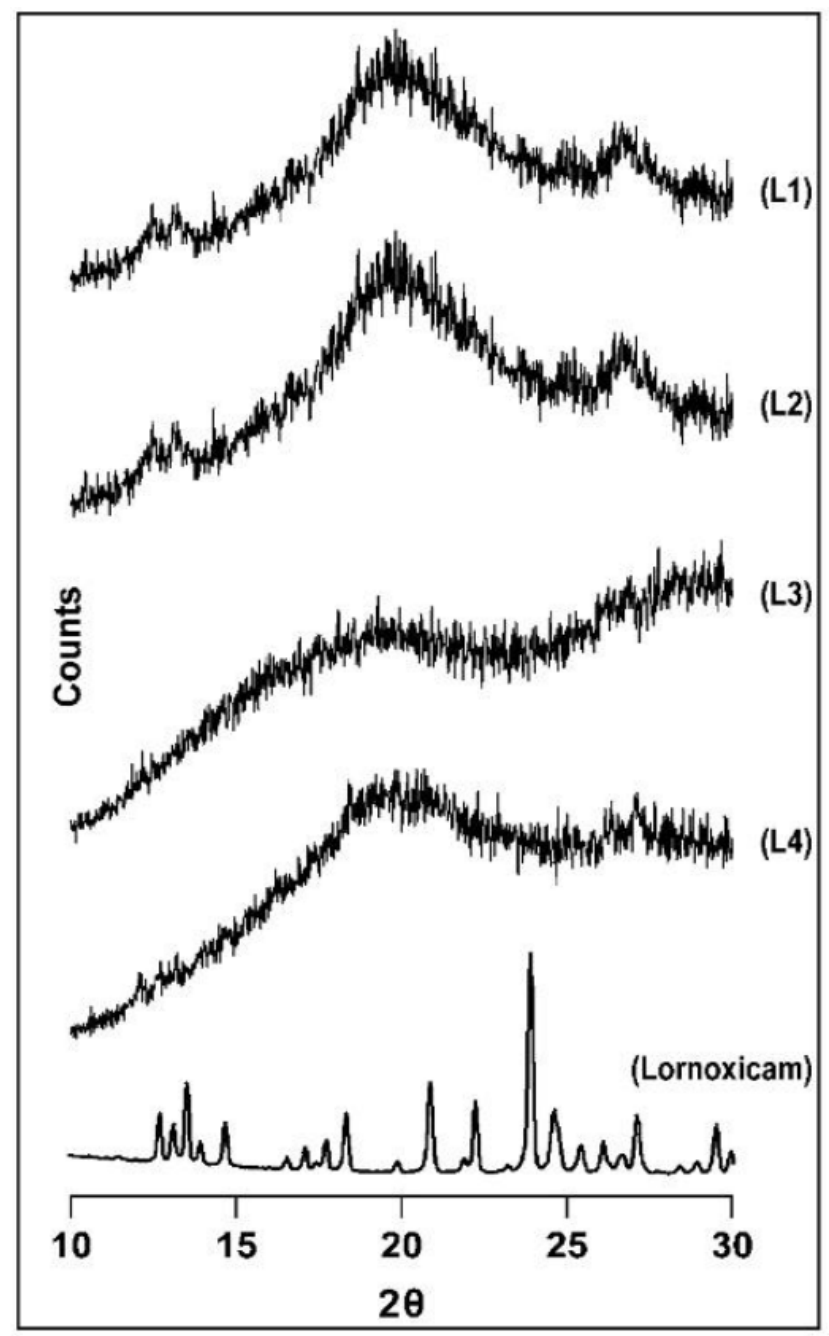

Figure 4: X-ray powder diffractometry (XRPD).

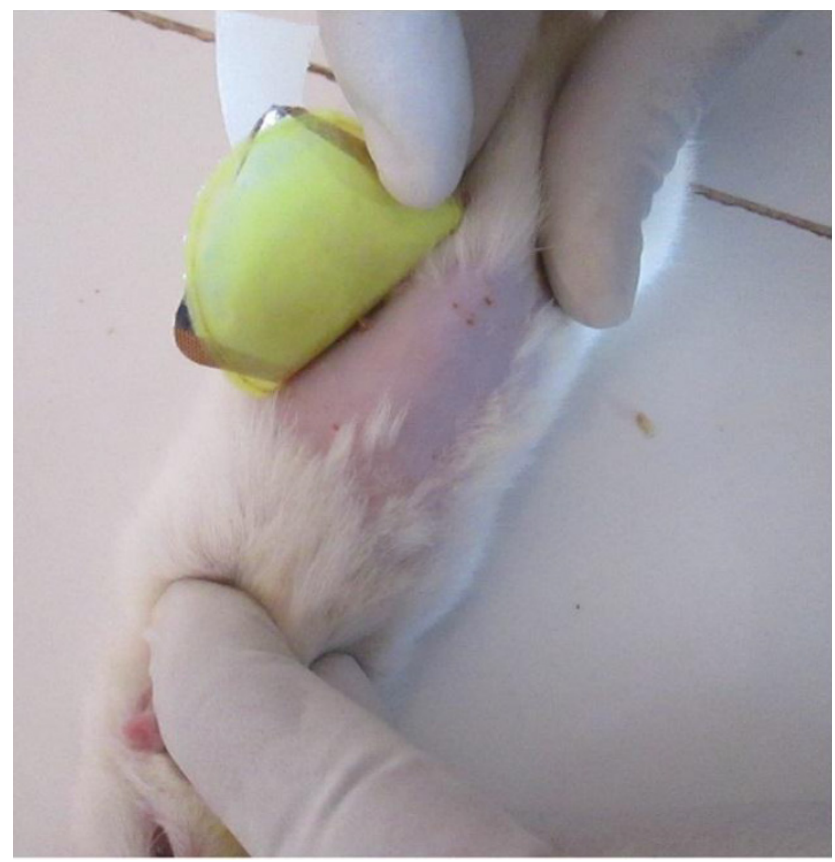

Figure 5: Skin irritation study. 
to the crystalline nature of chitosan, used in the formulations. ${ }^{24}$ Thus, it could be concluded that Lornoxicam did not exhibit amorphous character but appeared with significant reduction in the crystallinityin the formulations.

\section{CONCLUSION}

The transdermal patches of Lornoxicam prepared by using chitosan as release controlling polymer and Tween 20 as permeation enhancer increases permeability andmay enhance bioavailability of Lornoxicam. The transdermal patches showed acceptable physiochemical characteristics. The developed transdermal patch may increases patient compliance, reduces toxic effects of lornoxicam and may become acceptable drug delivery system for lornoxicam.

\section{ACKNOWLEDGEMENT}

The author is thankful to Alembic pharmaceuticals, Mumbai for providing drug sample. The author is also grateful to Mr. Kamlesh Fofandi, Chitosan Mahtani, Veraval for providing Chitosan sample. The author is thankful to Principal Govt. College of Pharmacy, Karad for providing laboratory facilities. Author is also thankful to Appasaheb Birnale College of Pharmacy, Sangli for sanctioning the animal activity protocol.

\section{CONFLICT OF INTEREST}

The authors confirm that these article contents have noconflict of interest.

\section{ABBREVIATIONS}

UV: Ultraviolet; ${ }^{\circ} \mathbf{C}$ : Degree Celsius; SD: Standard deviation; Cm: Centimeter; gm: Gram; hr: Hour; mg: Milligram; $\mathbf{r}^{2}$ : Correlation Coefficient; IR: Infra-red $\mathbf{m L}$ : Milliliter nm: Nanometer i.p.: Intra-peritoneal; PII: Primary irritancy index; \%: Percentage; FT-IR: Fourier transforms infrared (FT-IR) spectroscopy; DSC: Differential scanning calorimetry; XRPD: X-ray powder diffractometry.

\section{REFERENCES}

1. Prausnitz MR, Langer R. Transdermal drug delivery. Nature Biotechnology. 2008;26(11):1261-8.

2. Kulkarni VH, Keshavayya J, Shastry CS, Preeti VK. Transdermal delivery of antiasthmatic drug through modified chitosan membrane. Indian Journal of Pharmaceutical Sciences 2005;67(5):544-7.

3. Hemant KSY, Shivakumar HG. Development of chitosan acetate films for transdermal delivery of propranolol hydrochloride. Tropical Journal of Pharmaceutical Research. 2010;9(2):197-03.
4. Sadhasivam L, Dey N, Francis AP, Devasena T. Transdermal patches of chitosan nanoparticles for insulin delivery. International Journal of Pharmacy and Pharmaceutical Sciences. 2015;7(5):84-8.

5. Can AS, Erdal MS, Güngör S, Özsoy Y. Optimization and characterization of chitosan films for transdermal delivery of ondansetron, Molecules. 2013;18(5):5455-71.

6. Varshosaz J, Jaffari F, Karimzadeh S. Development of bioadhesive chitosan gels for topical delivery of lidocaine. Scientia Pharmaceutica. 2006;74(4):209-23.

7. Allimalarkodi S, Srilakshmi $\mathrm{CH}$, Sujatha M, Ganesan V. Formulation and In vitro evaluation of transdermal patch of Lornoxicam by using hydrophilic and hydrophobic polymers. World Journal of Pharmaceutical Sciences. 2014;2(7):641-7.

8. Soujanya C, Satya BL, Reddy ML, Manogna K, Prakash PR, Ramesh A. Formulation and In vitro and in vivo evaluation of transdermal patches oflornoxicam using natural permeation enhancers. International Journal of Pharmacy and Pharmaceutical Sciences. 2014;6(4);282-6.

9. Patel BB, Shah CN, Shah RM. Formulation and in vitro characterization of lornoxicam transdermal matrix patch. International Journal of Advances in Pharmaceutics. 2016;5:30-8.

10. Xi H, Cun D, Xiang R, Guan Y, Zhang Y, Li Y, et al. Intra-articular drug delivery from an optimized topical patchcontaining teriflunomide and lornoxicam for rheumatoid arthritistreatment: Does the topical patch really enhance a local treatment?. Journal of Controlled Release. 2013;169(1-2):73-1.

11. Yener G, Üner M, Gönüllü Ü, Yildirim S, Kiliç P, Aslan SS, et al. Design of meloxicam and lornoxicam transdermal patches: Preparation, physical characterization, ex vivo and in vivo studies. Chem Pharm Bull (Tokyo). 2010;58(11):1466-73.

12. Patel BB, Shah CN, Shah RM. Formulation and in-vitro characterization of lornoxicam transdermal matrix patch. International Journal of Advances in Pharmaceutics. 2016;2:2320-23.

13. Bharkatiya M, Nema RK, Bhatnagar M. Development and characterization of transdermal patches of Metoprolol tartrate. Asian Journal of Pharmaceutical and Clinical Research. 2010;3:130-4.

14. Kunwarpuriya A, Doke V, Patel D, Sangha S, Singh SR, Khutle NM. Formulation and evaluation of Dextromethorphan hydrobromide fast dissolving film. International Journal of Innovative Pharmaceutical Sciences and Research. 2015;3:998-008.

15. Banu VTS, Sandhya KV, Jayaveera KN. Formulation and evaluation of transdermal drug delivery systems of ivabradine hydrochloride. Research Journal of Pharmacy and Technology. 2014;7(1):01-7.

16. Bangale GS, Rathinaraj BS, Rajesh KS, Shinde GV, Umalkar DG, Rajveer $\mathrm{CH}$, et al. Design and evaluation of transdermal films of Atenolol. Journal of Chemical and Pharmaceutical Research. 2010;2(3):593-604.

17. Prajapati ST, Patel CG, Patel CN. Formulation and evaluation of transdermal patch of repaglinide. International Scholarly Research Network ISRN Pharmaceutics. 2011.

18. Nabarawi MAE, Shaker DS, Attia DA, Hamed SA. In vitro skin permeation and biological evaluation of lornoxicam monolithic transdermal patches. International Journal of Pharmacy and Pharmaceutical Sciences. 2013;5(2):242-8.

19. Rajurkar VG, Zarekar S, Ghawate VB, Pathanl B. The development, evaluation and in vitro release study of the terbinafine transdermal patch. Industrial Chemistry. 2015;1:1-6.

20. Gaikwad D, Kurane P, Mali D, Jadhav N. Development of particulate mucoadhesive gel for intranasal delivery. Asian Journal of Pharmaceutical and Clinical Research 2017;10:222-7.

21. Prabhakar D, Sreekanth J, Jayaveera KN. Effect of dimethylsulfoxide on transdermal patches of azelnidipine. Der Pharmacia Letter. 2014;6:120-7.

22. Yarraguntla SR, Enturi V, Vyadana R, Bommala S. Formulation and evaluation of lornoxicam nanocrystals with different stabilizers at different concentrations. Asian Journal of Pharmaceutics 2016;10(3):198-07.

23. Profiles of drug substances, exponents and related methodology $36^{\text {th }}$ ed. Academic press, Elsevier, London. 2011;220.

24. Salar RK, Kumar N. Synthesis and characterization of vincristine loaded folic acid-chitosan conjugated nanoparticles. Resource-Efficient Technologies 2016;2(4):199-214. 
PICTORIAL ABSTRACT



\section{About Authors}

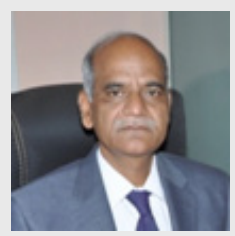

Dr. Adhikrao Vyankatrao Yadav (M. Pharm. Ph.D): Presently he is working as a Principal at Gourishankar Institute of Pharmaceutical Education and Research, Limb, Satara (MS). He had 35 years in teaching experience. He is Approved PG Teacher and Ph.D Guide. He has > 150 International and national Publications. His area of interest is crystal engineering, evaluation of natural substances as pharmaceutical excipients, particulate drug delivery system. He is a Life member of various professional associations like IPA, APTI and IPS.

\section{Summary}

- The present investigation was to develop transdermal system for lornoxicam using chitosan as rate controlling polymer and Tween 20 as permeation enhancer and to evaluate the effect of Tween 20 on the physico-chemical properties of the patches and on drug permeation across the membrane. Transdermal patches of Lornoxicam were prepared by solvent casting method. The prepared patches were evaluated for physicochemical characteristics such as invitro drug release, skin irritation studies. The interaction between drug and polymer were investigated by FTIR, DSC, XRPD methods. The in vitro release studies revealed Formulation L4 containing higher concentration of Tween 20 showed $74.6 \%$ diffusion in $12 \mathrm{hrs}$ and follows Korsmeyer-Peppas drug release kinetics. Respective formulation did not showed any sign of erythema or edema in skin irritation test.FTIR study reveals good compatibility between drug and polymer. The prepared transdermal drug delivery system of Lornoxicam using Chitosan had shown good promising results for sustained release matrix transdermal patch formulation.

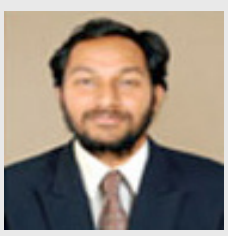

Shri. Mukund Namdeo Urade (M. Pharm.): Presently he is working as an Assistant Professor and HOD at Shri. Santkrupa College of Pharmacy, Ghogaon, Dist - Satara (MS). He had 13 years in teaching experience. He is Approved PG Teacher. His area of interest is evaluation of natural substances as Pharmaceutical excipients, particulate drug delivery system. He is a Life member of various professional associations like IPA, APTI and IPS.

Cite this article: Yadav AV, Urade MN. Formulation and Evaluation of Chitosan Based Transdermal Patches of Lornoxicam for Prolonged Drug Release and To Study the Effect of Permeation Enhancer. Indian J of Pharmaceutical Education and Research. 2019;53(1):88-96. 